\title{
Challenges in the Assessment of Inuit Food Security
}

\author{
Elspeth Ready ${ }^{1}$ \\ (Received 17 September 2015; accepted in revised form 29 March 2016)
}

\begin{abstract}
In the past few years, food security survey modules have been widely used to assess Inuit food access. However, these modules were not originally designed for use in mixed economies where both purchased and country (hunted, fished, and gathered) foods contribute to peoples' diets. These methods have been extensively tested and modified for use in Alaska, but research conducted in the Canadian Arctic has not been rigorously evaluated. This paper examines the validity of a modified version of the commonly used USDA Household Food Security Survey Module for assessing the food security of Inuit households in Kangiqsujuaq, Nunavik. The data come from 110 household surveys that were collected as part of an extended ethnographic project in the community. Rasch modeling of the food security module results indicates that, even with modifications that make reference to country food, the module assesses only the dimension of food security related to material wealth. Household income is a contributing factor for country food access, because it is important for access to harvesting equipment; however, other factors related to country food harvesting may affect the reliability of some food security module questions. Consequently, studies that assess Inuit food access using only standard survey modules may misrepresent how Inuit experience food insecurity, which is a serious concern given the current food crisis among Inuit in Canada. Assessment tools that provide reliable and valid assessments of country food access, specifically including traditional knowledge and social support networks, need to be developed.
\end{abstract}

Key words: food security; Inuit; indigenous peoples; subsistence; mixed economy; research methods

RÉSUMÉ. Au cours des dernières années, les modules de questionnaires portant sur la sécurité alimentaire ont beaucoup été utilisés dans le but d'évaluer l'accès aux aliments par les Inuits. Cependant, ces modules s'appliquent mal aux économies mixtes caractérisées par des régimes alimentaires composés de nourriture achetée et de nourriture traditionnelle (produits de la chasse, de la pêche et de la cueillette). Ces méthodes ont été rigoureusement mises à l'épreuve et modifiées afin d'être employées en Alaska. Toutefois, les recherches effectuées dans l'Arctique canadien n'ont pas été évaluées minutieusement. Le présent article examine l'utilité d'une version modifiée du Household Food Security Survey Module développé par l'USDA, un type de questionnaire couramment utilisé, afin d'évaluer la sécurité alimentaire des ménages inuits à Kangiqsujuaq, au Nunavik. Les données analysées émanent de 110 ménages sondés dans le cadre d'une étude ethnographique prolongée. Les résultats montrent que, malgré certaines modifications portant spécifiquement sur la nourriture traditionnelle, le module ne mesure que la dimension de la sécurité alimentaire liée à la richesse matérielle. Cette dernière facilite l'accès à la nourriture traditionnelle en favorisant l'accès aux équipements de chasse. Toutefois, d'autres facteurs liés à l'accès à la nourriture traditionnelle peuvent influer sur la fiabilité de certaines questions du module. En conséquence, les études qui évaluent la sécurité alimentaire des Inuits en ne se basant que sur le questionnaire portant sur la sécurité alimentaire risquent de mal représenter l'insécurité alimentaire telle que perçue par les Inuits. Ce problème est préoccupant étant donné la crise d'accès à la nourriture qui prévaut actuellement chez les Inuits du Canada. Des outils de recherche permettant de mieux évaluer l'accès à la nourriture traditionnelle devront être développés, en particulier en ce qui a trait aux connaissances traditionnelles et aux réseaux d'entraide sociaux.

Mots clés : sécurité alimentaire; Inuit; peuples autochtones; subsistance; économie mixte; méthodes de recherche

Révisé pour la revue Arctic par Nicole Giguère.

\section{INTRODUCTION}

Food insecurity is commonly defined as "limited or uncertain availability of nutritionally adequate and safe foods or limited or uncertain ability to acquire acceptable foods in culturally appropriate ways," while food security is defined as "access by all people at all times to enough food for an active, healthy life" (Bickel et al., 2000:6). The use of the concept of food security (or insecurity) in studies of Inuit food systems has largely emerged over the past decade, especially in concert with increasing concern for the social and economic effects of climate change. Many studies have focused on considering how food security should be defined for Inuit and other indigenous groups (Power, 2008; Loring and Gerlach, 2009), assessing the prevalence of food security in northern settlements (Lawn and Harvey, 2004; Chan

\footnotetext{
${ }^{1}$ Department of Anthropology, Stanford University, 450 Serra Mall, Stanford, California 94305, USA; eready@ualberta.net

(C) The Arctic Institute of North America
} 
et al., 2006; Lambden et al., 2006; Egeland et al., 2011; Ford and Beaumier, 2011; Huet et al., 2012; Council of Canadian Academies, 2014), and identifying possible threats to food security posed by environmental changes such as warmingrelated habitat loss or sea ice reduction and social changes such as loss of traditional knowledge (Guyot et al., 2006; Ford, 2009; Beaumier and Ford, 2010; Wesche and Chan, 2010).

Much recent research on food security in the Canadian Arctic and Alaska has used food security survey modules (e.g., Lawn and Harvey, 2004; Magdanz et al., 2010; Brown et al., 2012; Huet et al., 2012), which are commonly based on the USDA Household Food Security Survey Module (HFSSM) (Bickel et al., 2000; USDA, 2012). Because the HFSSM was designed for measuring food security in the continental United States, studies in the Arctic have used slightly modified versions of the HFSSM to account for the importance of country food (foods that are hunted, fished, and gathered), as well as purchased store food, in Arctic communities. Although published research suggests that the results of these food security modules correlate with various other measures of Inuit health and socioeconomic status (Egeland et al., 2011; Huet et al., 2012), the effectiveness of these modifications for assessing Inuit country food access in Canada have not been evaluated in detail.

In this paper, I present results from a survey of household socio-economic status and food security conducted in $2013-14$ in Kangiqsujuaq, Nunavik. Access to food, both purchased and harvested, is a major public health issue in Nunavik, as it is elsewhere in the Canadian Arctic. According to the 2004 region-wide Nunavik Health Survey, 24\% of Nunavimmiut households surveyed did not have enough to eat in the house during the month before the survey (Blanchet and Rochette, 2008). However, rather than simply providing another set of statistics on northern food security, this article aims to explore how we might better identify and measure "food security" in the contemporary mixed market/subsistence economy that characterizes Canadian Inuit settlements. In particular, I attempt to empirically disentangle how access to country food and access to store food interact by examining how references to country food affect Inuit responses to food security questions. I also discuss how these results relate to the way in which Inuit experience food insecurity more broadly. Although I focus on one Inuit village, the analysis of the different effects of harvested and purchased foods is relevant to our understanding of - and attempts to measure - food security in mixed economies across the globe.

\section{STUDY AREA}

Kangiqsujuaq, also known as Wakeham Bay, is a settlement of roughly 800 people located on the western coast of the Hudson Strait in Nunavik (Quebec). All but a handful of the village's permanent residents are Inuit. Like most other Canadian Arctic settlements, Kangiqsujuaq has a "mixed economy," which refers to the persistence of traditional subsistence pursuits (hunting, gathering, fishing) despite substantial integration into the larger market economy (Harder and Wenzel, 2012). Although wage work in the public sector is the predominant occupation of Kangiqsujuarmiut today, hunting, fishing, being on the land, and eating and sharing the harvest are what make working seem worthwhile for many Kangiqsujuarmiut.

Stevenson (1997) argues that the transition from dogsleds to snowmobiles for hunting, a development that quickly followed settlement in the early 1960s, was the key factor in the transition to the mixed economy in the Canadian Arctic. Snowmobiles require sustained high levels of capital investment, because often they are no longer serviceable after two or three years of use. Since the 1983 European Union seal fur ban, financing subsistence activities has become increasingly difficult for Inuit hunters (Smith and Wright, 1989; Smith, 1991; Wenzel, 1991). Today, Inuit subsistence harvesters are dependent on wage labour - their own or that of their family members - to finance their hunting, fishing, and gathering activities (e.g., Collings, 2011). As FienupRiordan (1983) pointed out, for every step forward in growth and development, Arctic village economies seem to take one step backward as a result of inflation and increased equipment costs. Indeed, this still seems to be an apt characterization of the state of northern economies today, more than 30 years later-a point highly relevant to the current state of food security in the Canadian Arctic.

\section{METHODS}

\section{Data Collection}

The data analyzed in this study were collected in a household survey conducted in Kangiqsujuaq between September 2013 and July 2014 as part of a year-long ethnographic research project in the settlement. More information on the survey methods can be found in Ready (2016). Here, I focus on the details of the food security portion of the questionnaire, which was based on the six-item subset of the widely used USDA Household Food Security Survey Module (HFSSM). This module is a perception-based tool that focuses on household access to food, rather than on community-level availability of food or on food choice and use. Coates et al. (2006) and Wunderlich and Norwood (2006) provide good overviews of the development, intent, and weaknesses of the HFSSM.

An HFSSM-based instrument was used for the purpose of comparability with other datasets; in particular, with Lawn and Harvey (2004), who conducted a food security survey in Kangiqsujuaq in 2002, and with questionnaires that have been widely implemented in Alaska by the Department of Fish and Game (e.g., Magdanz et al., 2010; Kukkonen and Zimpelman, 2012). Because the questions were embedded within a longer questionnaire that included several sensitive topics, the standard six-item subset of the 
HFSSM, rather than the full 18-item core module (Bickel et al., 2000), was chosen to minimize respondent burden.

According to the developers of the USDA food security questionnaire, one of the implications of choosing the sixquestion module is that it does not directly measure child food security (Bickel et al., 2000). This choice therefore represents a limitation of this study; however, it does not affect the goal of assessing the performance of the module in evaluating the food security of Inuit adults. Additionally, in Kangiqsujuaq, the diet of children is supplemented at school with cereal and fruit in the mornings for students up to Grade Six and with subsidized snacks available for purchase by older students. Inuit children can also be quite resourceful in finding meals outside their own home, for instance, by accompanying friends home at lunchtime or after school. Nevertheless, many respondents who provided affirmative answers to the food security questions specifically mentioned the difficulty of feeding their children. Others mentioned the obligation they felt to provide meals to children other than their own, usually grandchildren or friends of their own children.

Because the USDA food security modules were designed and tested primarily for measuring food security in the continental United States, the items included required some modification, mostly to accommodate the subsistence component of the Kangiqsujuaq economy. The modifications I implemented were based on (1) re-phrasing of HFSSM questions used by Lawn and Harvey (2004) and in other studies conducted by Indian and Northern Affairs Canada, (2) food security survey instruments used in subsistence studies by the Alaska Department of Fish and Game (ADF\&G), and (3) suggestions made by Kangiqsujuarmiut respondents who pretested the survey. First, respondents were asked to affirm or deny the statement "the food we had just did not last, and we could not get more" three times instead of only once. The first time, the question was asked about all sources of food; the second time, about country food only; and the third time, about store food only. This procedure reflects the strategy currently used by the ADF\&G. A question referring to "balanced meals" was changed to "healthy meals" because this phrasing was considered to be more meaningful to Inuit (Lawn and Harvey, 2004). Many traditional Inuit meals may not be "balanced" in the logic of food pyramid-based nutritional recommendations, but they are still healthy and nutrient-rich (Kuhnlein et al., 2008). For food security questions that asked whether household members had reduced food intake, the phrase "because there wasn't enough money for food" in the USDA version was replaced with "because the household could not get the food that was needed" or "because there wasn't enough food," as done by the ADF\&G (e.g., Brown et al., 2012; Ikuta et al., 2014), to allow for the fact that country food access in Kangiqsujuaq is not determined solely by cash availability.

Table 1 shows the food security questions and prompts used in this study; from here on, I will use the identifiers given in the table $(\mathrm{Q} 1-8)$ to refer to these items. All respondents were asked the first three screening questions, plus the two modified screening questions $(\mathrm{Q} 1-5)$. If households provided an affirmative ("sometimes" or "often") answer to one of the first three screening questions, then they were also asked the three questions about reductions in food intake (Q6-8).

Non-responses to the food security questions (refusals to answer or "don't know" responses) were very infrequent, and response rates for individual items are provided in the results below. In addition to the food security questions, additional data collected in the survey, including variables relating to household demographics, education, income, participation in subsistence activities, and food sharing, are used in the regression analysis.

In total, 110 of 146 Inuit households in the settlement (75.3\%) responded to the survey. A census was attempted, but not all households were available to participate. However, the population sampled in the household survey shows the same age (Kolmogorov-Smirnov test: $\mathrm{D}=0.05, p=0.72$ ) and $\operatorname{sex}\left(\chi^{2}=0.05, p=0.82\right)$ distributions as the 2011 census data for Kangiqsujuaq (Statistics Canada, 2012). Other metrics, such as median age and mean number of children per household, are also very similar to the census data, and it appears that the survey data are a representative sample of households in the settlement.

Survey interviews were conducted between September 2013 and July 2014. The surveys were completed over an extended period because it was difficult to get interviews in some seasons, interpreters were not always available, and I was also collecting data from various other sources. However, the long data collection period probably had only a limited impact on the results because all respondents were asked to provide information covering a full seasonal cycle (12 months), and all but a few households were stable over the entire period of my fieldwork.

In general, I conducted surveys jointly with a local translator/research assistant. Questions were read aloud to respondents, and their answers were written down on the survey form. Respondents were asked to choose which language they preferred for the interview; as a result, $35 \%$ of interviews were conducted in Inuktitut and the rest in English. Of the 110 respondents, $55 \%$ (60/110) were women. Ninety-two percent (101 of 110 respondents) identified themselves as the household head or co-head; the other $8 \%$ were adults who were knowledgeable about the activities of their household, but did not identify themselves as head of the household.

In addition to the survey, 120 semi-structured interviews were conducted at roughly two-week intervals over nine months with a small sample of eight households chosen to represent a broad socio-economic spectrum. I also regularly accompanied members of several local families on harvesting trips and other land-based activities, totaling more than 35 days of fieldwork throughout the year. The study was approved by the Stanford University Institutional Review Board, and all participants provided oral consent. All names used in this article are pseudonyms. 
TABLE 1. Food security module questions and prompts used in this study. Respondents who answered "never" to all of Q1-3 did not answer Q6-8.

Prompt: Please think about all of your household's food, both country and store-bought. We will read some statements about the food eaten in your household in the last year and whether you were able to afford the food you need. For each of these statements, please tell me whether this happened often, sometimes, or never for your household in the last year.

\begin{tabular}{lll} 
& & \multicolumn{2}{c}{ Response options } \\
\cline { 2 - 3 } Q. Item & The food we had just did not last, and we could not get more. & Sometimes \\
Q2 $\quad \begin{array}{l}\text { We could not get the food we wanted to eat because of a lack of resources. } \\
\text { By lack of resources, we mean your household did not have what you needed to hunt, } \\
\text { fish, gather, or buy food. }\end{array}$ & \\
Q3 We couldn't afford to eat healthy meals. & $\square$
\end{tabular}

Prompt: Now think about only country foods and only store foods, one at a time. For each of these statements, state whether or not it was true for your household in the last year.

\begin{tabular}{lllr} 
& & \multicolumn{2}{c}{ Response options } \\
\cline { 2 - 3 } Q. & Item & True & False \\
Q4 & The COUNTRY FOOD we had just did not last, and we could not get more. & $\square$ \\
Q5 & The STORE FOOD we had just did not last, and we could not get more. & $\square$
\end{tabular}

Prompt: We will now ask a series of questions about the availability of food in your household. For each of these questions, consider whether this happened in your household in the last year. Think about the TOTAL amount of food (both country foods and store foods) that was available to your household.

\begin{tabular}{|c|c|c|c|c|c|}
\hline \multirow[b]{2}{*}{ Q. } & \multirow[b]{2}{*}{ Item } & \multicolumn{4}{|c|}{ Response options } \\
\hline & & Never & $\begin{array}{c}\text { Only } 1 \\
\text { or } 2 \text { months }\end{array}$ & $\begin{array}{l}\text { Some } \\
\text { months }\end{array}$ & $\begin{array}{c}\text { Almost } \\
\text { every month }\end{array}$ \\
\hline Q6 & $\begin{array}{l}\text { Did you or other adults in your household ever } \\
\text { CUT THE SIZE OF YOUR MEALS OR SKIP MEALS } \\
\text { because the household could not get the food that was needed? }\end{array}$ & $\square$ & $\square$ & $\square$ & $\square$ \\
\hline Q7 & $\begin{array}{l}\text { Did you or other adults in your household ever } \\
\text { EAT LESS THAN YOU FELT YOU SHOULD } \\
\text { because the household could not get the food that was needed? }\end{array}$ & $\square$ & $\square$ & $\square$ & $\square$ \\
\hline
\end{tabular}

\section{Data Analysis}

I will first give a basic statistical overview of the questionnaire results for the food security module and then discuss latent trait modeling of individual items in that module. This modeling permits analysis of how sensitive each item is to underlying continuous variables ("latent traits") - in this case, to food insecurity. The goal of the latent trait modeling was to explore the patterning of Kangiqsujuarmiut responses to the food security questions in relation to this hypothesized latent trait. Specifically, I assess the fit of the Kangiqsujuarmiut food security data to the Rasch model, a constrained one-parameter latent trait model that links the respondents' total number of "correct" (or in this case, affirmative) answers to their position on the latent trait (i.e., their degree of food insecurity relative to others) (DeMars, 2010). A key assumption of the Rasch model is that all questions on a test or survey can be ranked in order of difficulty, and that respondents who "fail" a particular question should also "fail" all, or almost all, questions that are more difficult. The USDA food security module was constructed to conform to a Rasch model (Bickel et al., 2000), and thus the questions in the module are intended to detect increasing levels of severity in food insecurity. The main goal of the Rasch analysis is to assess the validity of this assumption among Inuit respondents, particularly when references to country foods were added to the questions.

To perform the analysis, the polytomous food security data were recoded to binary response patterns following standard USDA procedures (Bickel et al., 2000). For statements 1-3, an affirmative response ("sometimes" or "often") was coded as "1," and "never" was coded as "0." Statements 4 and 5 were true/false items and did not require any recoding. For questions $6-8$, response categories "never" and "only $1-2$ months" were coded as " 0 ," and "some months" and "almost every month" were coded as "1." Because households that did not respond affirmatively to statements 1 to 3 did not answer the full set of questions, and because response patterns of all zeros (or all ones) provided no information on the difficulty of items relative to other items, I examined the fit to the Rasch model only for the set of households that affirmed at least one statement about food insecurity. This group includes households that responded "true" to the country food screening prompt (Q4), even if they responded "never" to statements 1 to 3. 
TABLE 2. Results of food security screening questions, showing percentage of responses for each category.

\begin{tabular}{|c|c|c|c|c|c|}
\hline \multirow[b]{2}{*}{ Item } & & \multicolumn{3}{|c|}{ Response Options } & \multirow{2}{*}{$\begin{array}{c}\text { Item } \\
\text { response rate }\end{array}$} \\
\hline & & Never true & Sometimes true & Often true & \\
\hline Q1 & The food we had just did not last, and we could not get more. & $56 \%$ & $26 \%$ & $19 \%$ & $98 \%(108 / 110)$ \\
\hline Q2 & We could not get the food we wanted to eat because of a lack of resources. & $47 \%$ & $40 \%$ & $13 \%$ & $97 \%(107 / 110)$ \\
\hline Q3 & We couldn't afford to eat healthy meals. & $66 \%$ & $27 \%$ & $7 \%$ & $98 \%(108 / 110)$ \\
\hline
\end{tabular}

Given the limited sample size of this study (106 households with complete data, 72 of which affirmed at least one food security question), to avoid overfitting I did not attempt to fit the data to more complex latent trait models.

In the Rasch analysis presented below, estimates of item positions on the latent trait are reported as "easiness" coefficients, which assign high values to "easy" items (affirmed by many respondents) and low values to "difficult" items (affirmed by few respondents). The global fit of each model is reported as a chi-squared statistic based on collapsed deviance. This measure of goodness-of-fit involves grouping respondents by raw scores, calculating deviance residuals within groups, and summing the deviances across all groups, which yields a statistic with an asymptotic chi-squared distribution (see Mair et al., 2007). High chisquared values indicate larger residuals and thus a poorer overall fit to the model.

To assess the fit of individual survey module items within each model, I calculated outfit and infit mean square statistics and a chi-squared test of the fit of observed values to the model item parameters. Infit and outfit compare the actual response patterns with the responses expected from the fitted model. Outfit mean square is sensitive to the presence of outliers in the data that do not fit the model (DeMars, 2010), while infit mean square is most sensitive to deviations between the model predictions and data for questions of a difficulty level that are close to the respondent's position on the latent trait (Linacre, 2002). Thus, outfit and infit assess different aspects of model fit, but problems with infit mean square are more important to overall model performance than outfit. According to Wright and Linacre (1994), outfit and infit mean square statistics ranging between 0.6 and 1.4 are reasonable for a survey rating scale. A perfect mean-square fit statistic is 1.0; higher values indicate underfitting, and lower values, overfitting.

Finally, I used regression analysis to identify what household demographic and socioeconomic factors, such as household size, income, and education, are correlated with food insecurity in the dataset. All analyses were completed in R (R Development Core Team, 2012). Rasch modeling was carried out using the package eRm (Mair and Hatzinger, 2007), as well as some functions from the packages ltm (Rizopoulos, 2006) and psych (Revelle, 2015). Regressions were conducted using MASS (Venables and Ripley, 2002), with the help of some diagnostic functions from the package car (Fox and Weisberg, 2011).
TABLE 3. Country food (Q4) versus store food (Q5) screening results, showing percentage of respondents for each response pattern, $n=107$.

\begin{tabular}{cccc}
\hline \hline & & \multicolumn{2}{c}{$\begin{array}{c}\text { The COUNTRY FOOD } \\
\text { we had just did not last }\end{array}$} \\
\cline { 3 - 4 } & & True & False \\
\hline $\begin{array}{c}\text { The STORE FOOD } \\
\text { we had just did not last }\end{array}$ & True & $36 \%$ & $7 \%$ \\
\hline \hline
\end{tabular}

\section{RESULTS}

\section{Reported Food Security Status in Kangiqsujuaq}

Table 2 shows the results of the first three food security questions, which are intended to screen for whether respondents were concerned about food access. Within each question, the responses follow the expected pattern: more respondents responded "never" than "sometimes," and more responded "sometimes" than "often." Among the three screening questions, Q3 ("We couldn't afford to eat healthy meals") received the lowest rate of affirmative responses, which conformed to the USDA expectation that this is a more severe indicator of food insecurity than Q1 ("The food we had just did not last and we could not get more"). However, in this context, low rates of affirmative responses to this question could also reflect the empirically documented and culturally perceived nutritional value of country foods, or a lack of knowledge about the nutritional value of store foods. The highest rate of affirmative responses for all of the food security questions is for Q2, which refers to a lack of resources for obtaining desired foods. More than half of respondents affirmed that Q2 was sometimes or often true in their household. The direct mention of resources for harvesting in this question (the text in Table 1 was read to respondents during survey administration) likely plays an important role in response patterns for this question, an issue I explore more below.

Table 3 shows the breakdown of responses to the repetition of Q1 with reference to country food only (Q4) and with reference to store food only (Q5). In a large majority of cases, the response for the store food prompt is positively associated with the response for country food (i.e., 76 of 107 households, or $72 \%$, answered either "true" to both Q4 and Q5, or "false" to both). This pattern suggests a strong association in means of access to country food and store food. However, while only $44 \%$ of households affirmed Q1, a total of $65 \%$ of households affirmed either or both of 
TABLE 4. Results of questions about the severity of food insecurity (Q6 to Q8), showing percentage of responses in each category. The top row for each question shows the percentages for the subset of households that answered the full set of food security questions (those who responded affirmatively to at least one of Q1-3). The bottom row in bold shows percentages for all households, assuming that households that did not affirm the initial screening items (Q1-3) also would not affirm any of the more severe indicators (Q6-8).

\begin{tabular}{|c|c|c|c|c|c|c|}
\hline \multirow[b]{2}{*}{ Question } & \multirow[b]{2}{*}{$\begin{array}{l}\text { Screen Q. } \\
\text { affirmed }\end{array}$} & \multicolumn{4}{|c|}{ Response } & \multirow[b]{2}{*}{$\begin{array}{c}\text { Item } \\
\text { response rate }\end{array}$} \\
\hline & & Never & $\begin{array}{l}\text { Only } 1 \text { or } 2 \\
\text { months }\end{array}$ & $\begin{array}{l}\text { Some } \\
\text { months }\end{array}$ & $\begin{array}{l}\text { Almost every } \\
\text { month }\end{array}$ & \\
\hline \multirow[t]{2}{*}{ Q6: Cut the size of your meals or skip meals } & $\geq 1$ & $39 \%$ & $9 \%$ & $25 \%$ & $27 \%$ & $98 \% 56 / 57)$ \\
\hline & $\geq 0$ & $67 \%$ & $5 \%$ & $13 \%$ & $14 \%$ & $96 \%(106 / 110)$ \\
\hline \multirow[t]{2}{*}{ Q7: Eat less than you felt you should } & $\geq 1$ & $56 \%$ & $9 \%$ & $12 \%$ & $23 \%$ & $100 \%(57 / 57)$ \\
\hline & $\geq 0$ & $77 \%$ & $5 \%$ & $7 \%$ & $12 \%$ & $97 \%(107 / 110)$ \\
\hline \multirow[t]{2}{*}{ Q8: Hungry but did not eat } & $\geq 1$ & $65 \%$ & $11 \%$ & $9 \%$ & $16 \%$ & $100 \%(57 / 57)$ \\
\hline & $\geq 0$ & $81 \%$ & $6 \%$ & $5 \%$ & $8 \%$ & $97 \%(107 / 110)$ \\
\hline
\end{tabular}

the statements referring to country food alone (Q4) or store food alone (Q5). This pattern is driven by households that did not affirm Q1 but subsequently affirmed Q4. This could be interpreted to mean that the statement "The country food we had did not last" is not a good way to assess Inuit access to country food. However, the high frequency of affirmative responses to Q2, which included a specific reference to resources for harvesting, suggests that the high rate of affirmative responses to the prompt "The country food we had did not last" is not simply due to poor item wording, but represents a real pattern in the sample: many households that confirmed that they had sufficient access to store food, and which might be considered food secure in narrow terms (i.e., in calories available), were nevertheless concerned about their access to culturally desirable country foods.

In contrast, the number of households that felt they had access to sufficient country food but not to store food was small ( $7 \%$ of the sample). This group consisted of a few hunting households with relatively limited financial means and two single mothers. Many of these households used the community freezer frequently, and some also benefited from having close kin who harvested intensively. In other words, in Kangiqsujuaq, households that feel that they have access to sufficient country food but not to enough store food are exceptional cases.

The questions intended to assess the severity of household food insecurity (Q6-8) were asked only to respondents who had affirmed at least one of the first three screening questions. Consequently, in Table 4, the results for these questions are broken down into two categories. The first set of numbers shows the frequency of responses in each category for participants who answered the full set of food security questions, that is, all households who affirmed at least one of the first three prompts (Q1-Q3). The second set of numbers (in bold type) represents frequencies of responses to Q6-Q8 for all households. For these three items, the "never" $(0)$ response was ascribed to households that had responded "never" to the first three screening questions, assuming that they would give the same response to the more severe assessment questions. The validity of this assumption relies on the Rasch model underlying the construction of the USDA questions, which I examine in the following section.
The overall frequency of affirmative responses decreases from Q6 through Q8, which reflects the expectation of the USDA method. However, the responses do not follow the expected pattern within each of the questions: for all three of these items, more households responded that they reduced their food intake "almost every month" than "only 1-2 months." This finding suggests that for most households in Kangiqsujuaq that had to reduce their food intake, food insecurity is chronic rather than temporary. This pattern is consistent with poverty related to unemployment, under-employment, and other factors. The data are not sufficiently detailed to assess whether there are seasonal patterns in the severity of food insecurity in Kangiqsujuaq. However, research in Alaska suggests that seasonality is an important factor in food security there (Brown et al., 2012).

In order to assess the current prevalence of food insecurity in Kangiqsujuaq, a subset of the questions in the food security module used in this study $(\mathrm{Q} 1, \mathrm{Q} 3$, and Q6-8, which represent the questions in the original six-item HFSSM) was coded according to the criteria described in USDA (2012). On the basis of these tallying procedures, $59 \%(63 / 106)$ of households in the sample would be classified as having "high or marginal" food security, $21 \%$ $(22 / 106)$ would be classified as having "low food security," and 20\% (21/106) of households would be classified as "very low food security." In comparison, Lawn and Harvey (2004) found that $60 \%$ of Inuit households in Kangiqsujuaq were food secure, $33 \%$ were food insecure without hunger, and $7 \%$ were food insecure with hunger. The categories "food insecure without (or with) hunger" are no longer recommended (Wunderlich and Norwood, 2006); however, they are equivalent to the categories "low" and "very low" food security, respectively. This finding suggests that although the overall prevalence of food insecurity in Kangiqsujuaq has not changed over the past decade, the severity of the problem among food-insecure households has increased substantially. Despite some differences in methods, the estimates provided here for Kangiqsujuaq are similar to results recently reported for Nunavut $63.7 \%$ food secure, $3.5 \%$ marginally insecure, $15.9 \%$ moderately insecure, and $16.9 \%$ severely insecure) and are undeniably higher than the overall rate of moderate and severe food insecurity in Canada as a whole (8.1\%) (Council of 


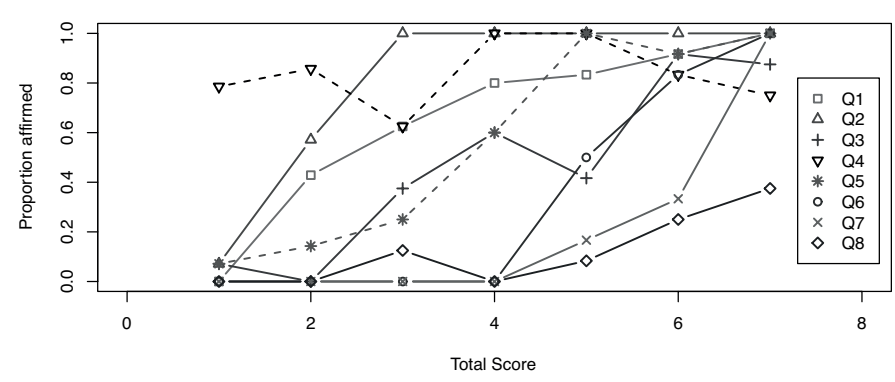

FIG. 1. Proportion of affirmed responses versus respondent total scores for food security questions. Dotted lines show Q4 and Q5, which are subquestions of Q1.

Canadian Academies, 2014:39). However, the high response rates for additional questions included in this studynamely Q2 and Q4, which attempted to assess country food access - indicate that many households that would be coded as food secure according to the standard USDA methods were concerned about their access to country food or their access to resources for obtaining country food, or both. Fourteen percent (15/106) of households in the sample affirmed Q2 or Q4 but were coded as food secure because they had a score of zero using the standard USDA set of questions. In other words, nearly a quarter of the households coded as food secure (15/63) were concerned about their access to country food. In the following section, I use Rasch analysis to examine what this pattern implies about the validity of the food security assessment used in this and similar studies.

\section{Rasch Modeling Inuit Food Security}

Instruments such as the HFSSM are designed to assess a one-dimensional scale of food insecurity and were developed in contexts where food access is entirely or almost entirely determined by purchasing power (Bickel et al., 2000). Although money is important for Inuit access to store food and hunting supplies, country food access is also determined by environmental conditions, hunting knowledge, skill, and opportunity, among other factors. As mentioned earlier, the food security measurement instrument used here was modified from the HFSSM specifically to include country food. Inuit might also respond differently to standard food security questions for cultural reasons. To identify how Inuit responses might differ from expectations derived elsewhere, and whether this possibility undermines the validity of the HFSSM in Arctic contexts, I examine the patterning of Kangiqsujuarmiut responses relative to the Rasch model.

Figure 1 shows the proportion of respondents who scored "1" for each food security question, based on the answers coded by USDA standards, versus respondents' total food security scores (i.e., the sum of their dichotomized responses). For instance, among respondents with a total score of one, the proportion of respondents who affirmed Q4 ("The country food we had just did not last") was 0.79 . Response patterns for households with a total score of zero $(n=34)$ and for households with a total score of eight $(n=6)$ are not shown in the plot because they provide no information about the relative difficulty of the items.

In Figure 1, we would expect items conforming to a Rasch model to have monotonically increasing response rates as respondents' total scores increase, and for the items to have parallel slopes (i.e., the lines showing the response patterns for each item should not cross each other). Additionally, the most sensitive indicators of the latent trait (food insecurity) should increase first, while indicators of more severe food insecurity should rise only at higher total scores. Figure 1 suggests that the response patterns for Q1, Q2, Q6, Q7, and Q8 provide a reasonable match to these Rasch expectations, although there are minor variations in the slopes of the lines and a couple of small deviations from monotonicity. The second screening item $(\mathrm{Q} 2$, "We could not get the food we wanted to eat because of a lack of resources"), which included a reference to access to resources for harvesting, appears to be a very sensitive indicator of concern about food access, with $100 \%$ of respondents with a total score of three or more affirming this item. However, Q4 ("The country food we had not did last"), which has the highest rate of positive responses for low-scoring households, does not show a consistent pattern of increase with total score (Pearson's $r=0.33, p=0.41$ for total scores 1-7). Q3 ("We couldn't afford to eat healthy meals") does increase over the range of total scores (Pearson's $r=0.92, p<0.01$ ), but the increase is not monotonic and the response curve crosses those of several other items.

Table 5 shows the results of Rasch model fitting to the dichotomized food security dataset. A good model fit would have low chi-squared values and high $p$-values for the overall goodness of fit test, as well as for the individual item chi-squared tests, with outfit/infit values for all questions between 0.6 and 1.4. Poor item fit indicates that the item is not clearly ranked among the other questions along a single unidimensional trait.

The first model reported in Table 5 (Model 1) shows the Rasch model fit for the entire set of eight food security questions. According to the chi-squared test result, Q4 does not fit the model $\left(\chi^{2}=516.02, p<0.005\right)$, and the overall fit of the entire model to the data is poor (collapsed deviance $\left.\chi^{2}=89.15, p<0.01\right)$. The poor fit of Q4 is consistent with the evidence presented earlier that responses for this item, which is specifically about country food, do not increase consistently with the latent trait underlying the overall data. Consequently, the model was refit excluding Q4. This second model (Model 2 in Table 5) shows a better overall goodness-of-fit (collapsed deviance $\chi^{2}=49.36$, $p=0.20$ ). However, Q1 (and to a lesser extent, Q3) now fit poorly, as shown by the item chi-squared tests, as well as the high outfit statistic for Q1. The poor fit of Q1, which is identical to Q4 but asked respondents to consider country and store food together, may be a result of the reference to country food, particularly since Q5, which referred to store food only, fits the model well.

The final model (Model 3 in Table 5), with both Q1 and Q4 excluded, shows a good overall fit to the data 
TABLE 5. Summary of Rasch model fits for all households with a total dichotomized food security score of 1 or more $(n=72)$. Results shown for full eight-item survey module set and for two subsets of items.

\begin{tabular}{|c|c|c|c|c|c|c|c|c|}
\hline \multicolumn{9}{|l|}{ 1. All items included } \\
\hline Q1 (Not last) & 0.86 & 0.32 & 3 & 48.43 & 65 & 0.94 & 0.73 & 0.85 \\
\hline Q3 (Healthy) & -0.30 & 0.30 & 5 & 73.53 & 65 & 0.22 & 1.11 & 1.05 \\
\hline Q4 (Country) & 2.38 & 0.36 & 1 & 516.02 & 65 & 0.00 & 7.82 & 1.63 \\
\hline Q5 (Store) & 0.54 & 0.31 & 4 & 41.85 & 65 & 0.99 & 0.63 & 0.70 \\
\hline Q6 (Cut/skip) & -0.88 & 0.31 & 6 & 26.55 & 65 & 1.00 & 0.40 & 0.61 \\
\hline Model G.o.F. ${ }^{1}$ & & & & 89.15 & 56 & $<0.01$ & & \\
\hline Cronbach's $\alpha$ & 0.80 & & & & & & & \\
\hline \multicolumn{9}{|l|}{ 2. Q4 excluded } \\
\hline Q1 (Not last) & 1.36 & 0.36 & 2 & 94.78 & 52 & 0.00 & 1.79 & 1.08 \\
\hline Q2 (Lack resources) & 2.74 & 0.46 & 1 & 12.26 & 52 & 1.00 & 0.23 & 0.58 \\
\hline Q3 (Healthy) & 0.00 & 0.32 & 4 & 69.03 & 52 & 0.06 & 1.30 & 1.18 \\
\hline Q5 (Store) & 0.96 & 0.35 & 3 & 39.00 & 52 & 0.91 & 0.74 & 0.78 \\
\hline \multicolumn{9}{|l|}{ 3. Q1 and Q4 excluded } \\
\hline Q2 (Lack resources) & 3.17 & 0.54 & 1 & 11.46 & 49 & 1.00 & 0.23 & 0.61 \\
\hline Q3 (Healthy) & 0.22 & 0.34 & 3 & 62.04 & 49 & 0.10 & 1.24 & 1.15 \\
\hline Q5 (Store) & 1.27 & 0.37 & 2 & 37.79 & 49 & 0.88 & 0.76 & 0.84 \\
\hline Q6 (Cut/skip) & -0.46 & 0.33 & 4 & 25.80 & 49 & 0.99 & 0.52 & 0.71 \\
\hline Q7 (Eat less) & -1.63 & 0.37 & 5 & 21.06 & 49 & 1.00 & 0.42 & 0.62 \\
\hline Q8 (Not eat) & -2.57 & 0.45 & 6 & 33.80 & 49 & 0.95 & 0.68 & 1.01 \\
\hline Model G.o.F. & & & & 26.37 & 30 & 0.66 & & \\
\hline Cronbach's $\alpha$ & 0.82 & & & & & & & \\
\hline
\end{tabular}

${ }^{1}$ Model goodness-of-fit statistic based on collapsed deviance (see text).

(chi-squared test of collapsed deviance not significant): it has no significant item misfits, and all of the infit statistics for the model are within a reasonable range. The chisquare value for Q3 is somewhat high, which likely reflects the non-monotonic pattern of the responses for this item, as noted in the discussion of Figure 1. The low outfit and infit mean square statistics for Q2 in the final model likely reflect inadequate stochastic variation in the responses to this prompt. Rasch models expect some random error in the data, but the responses for Q2 have a strong Guttman pattern (i.e., they are too deterministic: $100 \%$ of respondents with a total dichotomized food insecurity score of three or more affirmed this statement, Fig. 1). However, these low mean square statistics only reduce the precision of the model: they do not affect the meaning of the underlying measure (Linacre and Wright, 1994). Finally, the somewhat low infit/outfit statistics for Q6 (Cut/skip meals) and Q7 (Eat less) may reflect some redundancy between these two items. Because Q3 was also flagged as potentially problematic in the second model, the analysis was also conducted with both Q3 and Q4 excluded. In this case, Q1 still fit poorly, so the model with Q1 but not Q3 excluded was selected.

As a further check on the fit of the data to the Rasch assumptions, Figure 2 shows scree plots for the interitem tetrachoric correlation matrices of the data used in each of the models presented in Table 5. A scree test helps determine the number of underlying factors in a dataset (Cattell, 1966); data conforming to a Rasch model should be unidimensional. Figure 2 suggests that the full set of questions might be best described by two principal components (second eigenvalue greater than one and poorly defined break between the slope and the "scree"). Removal of Q4 results in an improvement towards greater unidimensionality (second eigenvalue less than one and more defined break in the line). Further elimination of Q1 leads to a minor additional improvement. This pattern confirms that Q4, which directly targets access to country food, measures a dimension of food security that is qualitatively and quantitatively different from those measured in the other questions of the module. However, the response pattern for Q2 indicates that access to resources for harvesting is determined by the same underlying factors as access to store food. In other words, access to resources for harvesting country food and access to country food are different dimensions of Inuit food security.

The analysis shows that a subset of the food security items used in the study provides a scale with internal validity for Inuit respondents in Kangiqsujuaq. This analysis has not determined whether the results presented here are externally valid. A Rasch analysis of 1312 rural Alaskan households conducted in 2013 by Mark Nord (formerly of the USDA Economic Research Service) for the Alaska Department of Fish and Game obtained results similar to those 


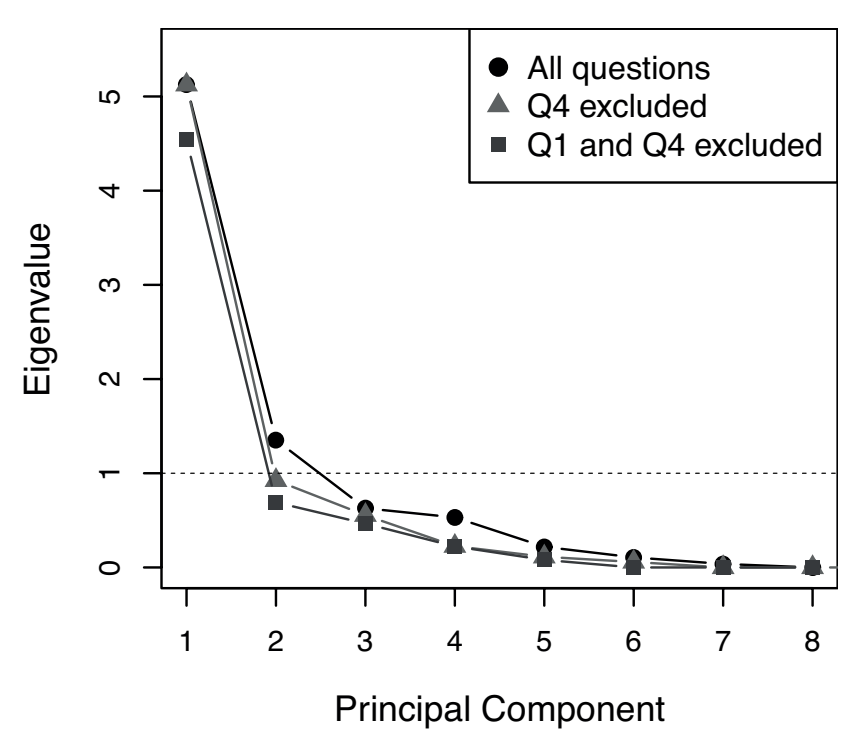

FIG. 2. Scree plot of eigenvalues of the inter-item correlation matrices of the food security data, for all questions and for item subsets. Eigenvalues are based on tetrachoric correlation matrices.

reported here for items comparable to Q1, Q3, and Q6-Q8 (Jim Magdanz, pers. comm. 2016). However, Nord's Rasch analysis did not incorporate additional ADF\&G food security questions that considered country and store foods separately. Nord concluded that the results from Alaska were roughly comparable to the U.S. national food security scale, although the ability of items to discriminate between levels of food insecurity was lower in the Alaskan data.

On the whole, the results suggest that the food security questions used in this research can provide a Rasch-scale measurement of food security in terms of access to store food and access to harvesting resources, once problematic questions are removed from the analysis. The Rasch model of the data with Q1 and Q4 removed appears to be adequate, if far from ideal. Besides the problems identified in the two items that were removed, Q2 might be considered too easy because it generated little variation, Q3 may have problems of respondent interpretation, as discussed earlier, and Q6 and Q7 might be somewhat redundant. Although the data presented here suggest that some of the HFSSM items can be used to provide a Rasch-scale measurement of one dimension of Inuit food security, the HFSSM questions clearly do not assess country food access very well, likely for a variety of reasons, which I will return to in the Discussion.

\section{Social and Economic Correlates of Inuit Food Insecurity}

To examine the correlates of the Rasch model food insecurity scores among Kangiqsujuarmiut, I performed a regression analysis of household food insecurity scores versus several household demographic and economic characteristics that are likely to be associated with food need, food access, or both in Nunavik. These characteristics were selected on the basis of comments made by study
TABLE 6. Correspondence between raw food insecurity score (six-item subset) and Rasch model latent trait position estimates used for regression analysis.

\begin{tabular}{ccc}
\hline \hline Raw score & Estimate & $n$ \\
\hline 0 & -4.19 & 47 \\
1 & -2.59 & 11 \\
2 & -1.08 & 8 \\
3 & 0.09 & 12 \\
4 & 1.21 & 12 \\
5 & 2.52 & 7 \\
6 & 3.88 & 9 \\
\hline \hline
\end{tabular}

participants, previous research in the region (Lawn and Harvey, 2004), and research in comparable regions such as Alaska (Brown et al., 2012). For the analysis, respondents' raw dichotomized food insecurity scores were converted to interval-level estimates according to the Rasch modeling results (with the problematic items Q1 and Q4 excluded, as detailed above), so that standard linear regression techniques could be applied. The interval-level estimates of household food security and the number of households with each score are shown in Table 6 . These represent the dependent variable in the regression analysis.

The factors examined in the regression analysis include household size (number of household members), whether the head of household is a single female, the age of the oldest member of the household, total income of the household head in the previous 12 months, the presence of a high school graduate in the household, the number of hunting vehicles owned by the household, and the number of other households in the community from which the household received country food, according to the sharing network data. Household subsistence harvesting is considered in two ways: whether or not the household had harvested any of four important food species (beluga, ringed seal, caribou, and geese) in the 12 months prior to the survey, and whether the household is a "super household," defined as a household in the top 30\% for harvest production (Wolfe, 1987). BurnSilver et al. (2016) used a similar procedure to examine harvest production in Arctic Alaska by dividing households into lower, middle, and upper tiers of household production. In Kangiqsujuaq, super households harvested approximately $80 \%$ of all calories represented in the survey harvest data.

Country food giving was not included in the regression because of problems of multicollinearity between giving and other variables: country food giving is strongly linked to subsistence harvest level for most households. Excluding this variable can also be justified on logical grounds because country food giving is probably better considered as an outcome of food security rather than as a potential cause of it, at least for most households. However, a small number of older households in the sample reported that they felt that they lacked food because of the obligations they had to give country food, store food, and occasionally money to their adult children, often for the purpose of feeding grandchildren. In other words, the food security of Inuit 
TABLE 7. Summary of food security regression results. Dependent variable in the models is the interval level estimate of household food security.

\begin{tabular}{|c|c|c|c|c|c|c|}
\hline \multirow[b]{2}{*}{ Predictors of food security estimates } & \multicolumn{3}{|c|}{ Full model } & \multicolumn{3}{|c|}{ Stepwise result } \\
\hline & Coef. & SE & $p$-value & Coef. & SE & $p$-value \\
\hline Intercept & -6.01 & 5.16 & 0.25 & -0.18 & 1.14 & 0.88 \\
\hline Household size $(\log +1)$ & 1.54 & 0.67 & 0.02 & 1.42 & 0.64 & 0.03 \\
\hline Single female-headed $(0 / 1)$ & -0.11 & 0.70 & 0.88 & & & \\
\hline Age oldest member $(\log +1)$ & 1.56 & 1.31 & 0.24 & & & \\
\hline 12 -month income per $\$ 10000(\log +1)$ & -1.46 & 0.60 & 0.02 & -1.66 & 0.48 & $<0.001$ \\
\hline High school graduate $(0 / 1)$ & -0.07 & 0.55 & 0.90 & & & \\
\hline Hunting household $(0 / 1)$ & -0.35 & 0.64 & 0.59 & & & \\
\hline Super-household $(0 / 1)$ & 0.94 & 0.68 & 0.17 & & & \\
\hline Hunting vehicles $(\log +1)$ & -1.65 & 0.55 & $<0.01$ & -1.23 & 0.45 & $<0.01$ \\
\hline Sharing in-degree $(\log +1)$ & -0.10 & 0.60 & 0.87 & & & \\
\hline$R^{2}$ & 0.31 & & & & 0.28 & \\
\hline Adj. $R^{2}$ & 0.23 & & & & 0.26 & \\
\hline AIC & 467.36 & & & & 459.03 & \\
\hline F-test vs. null model & 4.31 & & $<0.001$ & 12.15 & & $<0.001$ \\
\hline F-test vs. full model & & & & & 0.56 & 0.76 \\
\hline Number of complete observations & 98 & & & 98 & & \\
\hline
\end{tabular}

households is not necessarily independent of the food security status of other households because social ties create obligations to share food and other resources. Here, I focus on household-level properties associated with food security.

Table 7 shows the results of two analyses: (1) a full regression model including the effects of all the variables considered and (2) a stepwise regression result. The stepwise model with several variables removed has a higher adjusted $R^{2}$ value than the full model; indicating that the removed variables explained very little additional variance. The results suggest that higher levels of food insecurity are most strongly associated with lower income. Larger households also tend to have higher food insecurity scores, which is expected because both income and subsistence resources have to go farther in larger households.

Importantly, although ownership of hunting vehicles appears to be a significant correlate of food security, other variables associated with country food access (including the number of sharing partners and household subsistence harvests) were not retained in the model. This fact reinforces the conclusion drawn in the Rasch analysis that the food security survey module assesses access to resources for harvesting, but not access to country food directly. Basically, income is associated with food security both directly, through the ability to purchase food, and indirectly because higher-income households are better able to purchase and maintain hunting vehicles and thus to go out hunting regularly. Subsistence harvest production is correlated with the number of hunting vehicles owned (Pearson's $r=0.48$, $p<0.001$ ) and also with income (Pearson's $r=0.33, p<$ $0.001)$. In this sense, ownership of hunting vehicles may represent longer-terms patterns of household income and income management, as well as investment in country food procurement, all of which contribute to food security.

Households headed by single women tend to have higher food insecurity scores (biserial correlation $=0.26$ ), but this variable does not have a significant effect in the regression analysis, likely because households headed by single females also tend to have lower incomes (biserial correlation $=-0.58$ ). Furthermore, education does not appear to have a significant effect on food insecurity scores, but households with a high school graduate tend to have higher incomes (biserial correlation $=0.48$ ). In other words, households with a single female head tend to be more food insecure, and households with higher education tend to be more food secure, but at least in this analysis, both of these patterns appear to be due to the effect of income.

The overall proportion of the variance in food insecurity scores explained by the regression models is low (adjusted $R^{2}=0.23-0.26$ ). Two main issues likely contribute substantially to this result: first, the fit of the food security questions to the Rasch model remains far from perfect, which means that the scores used in the regression model do not map perfectly onto a household's actual level of food insecurity. Additionally, there may be omitted variables relating to factors such as the respondents' food choices, health behaviours, or both, or possibly seasonal patterns of food security. Further refinement and testing of food security questions, along with collection of data on additional variables which could not be collected in this study, such as substance abuse behaviours, could help address this issue in future studies.

In summary, the results indicate collinearity between the Rasch food security scale and income or material wealth. This finding reflects the intent of the original HFSSM. However, it is important to emphasize that this metric of food security clearly does not adequately capture or describe security of access to country food. This issue is the focus of the Discussion.

\section{DISCUSSION: FOOD SECURITY IN A MIXED ECONOMY}

No, I don't have enough country food right now, bad luck hunting. It's been really hard for about a month 
now. Not enough seal. [It's been hard] because there's hardly been open water for a month. Even other hunters aren't lucky with seals. Fish is easy. But my grandfather says the wind's in the south for two days so there will be more bear. With the south wind [he says] they go to land. Hopefully he's right.

Jobie, the young hunter who told me this in April 2014, could hardly be considered food insecure. He and his wife both held skilled jobs in the settlement, so they could afford to buy the food they needed from the local stores, and he was also one of the most active hunters in the settlement. Yet, whenever I asked him whether he had enough country food (which I did about once a month), he almost always said no, and then would tell me in detail why he hadn't had enough time to hunt recently and his food stores at home were depleting, or how the hunting conditions had been poor, or even how he had plenty of one species, such as fish, but not of another, such as seal, as he described above. I soon learned that Jobie's responses did not reflect actual shortages of food in his household; rather, they were a result of his constant evaluation and anticipation of hunting events and conditions. This frame of mind was a result of the responsibility he felt to supply his own and other households, especially those of his mother and grandmother, with a continuous supply of fresh and varied country foods. He, like all Kangiqsujuarmiut, had strategies for coping with variability in food access and availability; in his case, he coped with the unpredictability inherent in hunting with humility, by continuously thinking ahead and re-evaluating hunting conditions and opportunities. Although his mindset may at times have made it seem as though he were unsatisfied with or anxious about his food supply, his household and his extended family enjoyed bountiful, fresh, and varied country food year-round.

Jobie was fortunate: although he felt hunting conditions were bad for part of the 2013-14 season, he could compensate by hunting more often and by strategically allocating his hunting efforts among a wide variety of species. Despite having a job in the settlement, he was able to go hunting almost whenever he liked, while most other hunters were more constrained by the fixed hours required by their day jobs. Many other hunters lacked the knowledge of sea ice, hunting conditions, and animal behaviour necessary to switch target species so easily, a point Jobie was alluding to when he said, "Fish is easy." Still other hunters didn't have as effective social support networks, including both knowledge networks, as represented by the advice about polar bear Jobie received from his grandfather, and more direct support through sharing of food and equipment. On one occasion when Jobie's snowmobile broke down, he was able to borrow one of his father's machines for a couple of weeks while he made the arrangements to buy a new one (to the tune of Can\$20000). Jobie's ability to muster his material resources, knowledge, and social resources to confront the inherent uncertainty of hunting embodies the nature of food security in a mixed economy. Constantly thinking about food, or at least, about the activities and animals that lead to getting food, is a hallmark of a successful Inuit harvester.

In contrast, Piita, another man I spoke with regularly, admitted that his household didn't have enough country food mostly because he was a lousy shot and he lacked the motivation to go out hunting in cold weather. Despite the fact that Piita was quite a bit older than Jobie, he had substantially less knowledge about hunting. He obviously felt very guilty about his lack of skill and explained to me at length how he was trying to become a better hunter. Piita provides a good example of why some of the questions in the food security module did not work well: some respondents' answers to questions about country food were affected by other factors, in Piita's case a combination of a lack of experience and a lack of skill. Piita's experience of food insecurity was as much about his feelings of inadequacyand an underlying concern about cultural loss - as it was about actual access to food, but the food security module could not effectively capture why this was happening.

The only dimension of Inuit food security reliably measured by the food security module in this study, and probably also in other studies using the HFSSM or modified versions of it (e.g., Lawn and Harvey, 2004; Egeland et al., 2011), is the dimension related to household monetary resources. This aspect is perhaps particularly important because in some ways it acts as a gatekeeper to other dimensions of food security. Poverty is expected to be the main determinant of access to store food, which is borne out by the survey results. The three most common reasons given by survey respondents for not having enough store food were "not enough income," "had to pay bills," and "cost of food." Moreover, access to cash is critical for access to the resources needed for harvesting: good hunting conditions and sharp shooting skills are largely irrelevant to a hunter stuck in town with no machine. Indeed, a majority (53\%) of survey respondents affirmed that access to resources sometimes or often prevented them from getting the foods they wanted. "Resources for harvesting," such as vehicles and gasoline, are so expensive that even relatively affluent households worry about the cost. Boats and snowmobiles easily cost over Can $\$ 10000$, and the price of gasoline was Can $\$ 1.73 / \mathrm{L}$ for most of the year I spent in Kangiqsujuaq. Social support networks can help some hunters get access to equipment without buying it, at least temporarily; but the contribution of hunting vehicle ownership to food security observed in this study confirms that, in general, personal ownership ensures much better access to gear. Many of the households that I worked with avoided lending their snowmobiles out, even to close relatives, to ensure that their equipment would be available and in good condition when they needed to use it.

The Rasch model results for the Kangiqsujuarmiut food security data suggest which HFSSM items seem to be more effective, notably, the three severity items: "Cut/skip meals," "Eat less," and "Not eat." Such items may be an appropriate focus of screening for rapid assessment in cases where more detailed studies are impossible (cf. Urke et al., 
2014). Although the results of this study suggest that food security module items that refer to country food may create problems of underlying construct validity, it is clear that such modules are effective in assessing access to store food, as confirmed by other research (Egeland et al., 2011; Huet et al., 2012). Therefore, the results do not imply that we should abandon either HFSSM methods or the attempt to assess how Inuit food security is affected by country food access. Rather, I suggest retaining the HFSSM and similar methods for assessing store food access, while also developing additional questionnaire modules designed specifically to assess the other factors that determine access to country food.

The cases of the two men described above suggest at least two additional components that seem to be especially important in influencing Inuit food security in terms of country food access: (1) harvesting knowledge and skill and (2) social support networks. I am far from the first to identify the importance of these factors for Inuit food security (see Council of Canadian Academies [2014] and references therein); but even where these issues have been discussed they have typically not been quantified, which makes it difficult to assess how they might be changing over time or how they might differ between communities. The seasonality of harvesting and employment also represents an important source of variability in food security within households, but has not been examined in this paper because of data limitations.

Unfortunately, the assessment of harvesting knowledge and skill is difficult; indeed, many less knowledgeable hunters are not aware of their own limitations (i.e., they don't know how much they don't know), which may render self-assessments essentially useless. However, effective assessment tools might be developed with the help of local experts (e.g., knowledge of local toponyms, animal behaviour, etc.). Metrics of harvester performance (such as the range of species harvested) might also be used as a proxy of knowledge and skill, although such metrics are problematic because they are also affected by access to supplies and equipment. The Alaska Department of Fish and Game has incorporated a modified food security module along with extensive data collection on subsistence harvesting (e.g., Brown et al., 2012), which offers a promising source of information for guiding future research.

Quantitative assessment of social support might be most accurately carried out using complete community network data on a variety of support measures, data which can be collected as part of a questionnaire. One type of social support network (country food sharing) and its relationship to food security are examined in Ready (2016). Collings et al. (2016) use a similar approach, and recent research in Alaska has also focused on sharing networks and cooperative ties (BurnSilver et al., 2016). However, collection of complete network data may be prohibitively costly or too time-consuming for many studies because of sampling requirements. "Resource generator" survey instruments (e.g., Van der Gaag and Snijders, 2005), which do not have as stringent data requirements as complete social network data, may represent a productive avenue for future inquiry. Resource generators could be designed specifically to assess household access to knowledge networks, country food sharing, and other resources pertinent to country food access. Hadley et al. (2007) assessed social support in relation to food security at their study site in rural Tanzania using this type of method, and they found that social support had a stronger effect on food security for more affluent households.

\section{CONCLUSION}

According to the standard six-item HFSSM module, $41 \%$ of households in Kangiqsujuaq could be classified as having low or very low food security, while $59 \%$ could be classified as food secure or marginally food secure. However, the responses to questions that specifically mentioned country food, the results of the Rasch modeling, and the ways in which Inuit describe their relationship to country food call into question exactly what these numbers represent. The HFSSM does not capture the anxiety about country food that is a product of both the inherently uncertain nature of hunting and of a century of massive societal changes. These results indicate that we need to do a better job of evaluating how etic concepts such as food insecurity relate to the lived experience of food insecure people. Rigorous evaluation of empirical results, through procedures such as Rasch modeling, and contextualization of the results with reference to social as well as economic factors, can help us on this path.

Methods for assessing food security were a major concern of a recent report on food security in the Canadian North (Council of Canadian Academies, 2014:xx), which stated that "there is a need to adapt data collection tools and standards to the varied realities of Aboriginal peoples in Canada." The present study, which has attempted a quantitative assessment of the performance of a modified version of a widely used food security instrument among Inuit in Kangiqsujuaq, Nunavik, is a step in this direction. Although I have focused on data from one community in Nunavik, this conclusion is likely applicable to much of the circumpolar world, as well as to many remote indigenous settlements outside of it, where people continue to depend on traditional subsistence harvesting practices as well as purchased foods.

The results of this assessment indicate that even with modifications that attempt to accommodate the hybrid nature of Inuit food systems, Inuit responses to some items in the questionnaire do not conform to the expectations of the Rasch model. The module results do provide some useful information about Inuit food security insofar as it relates to household material wealth. However, other dimensions of Inuit food security seem to interfere with the performance of the modified HFSSM, in agreement with Briggs' (1970) observation that for Inuit, food-and especially country food-is about much more than a full stomach. 
Food insecurity among Inuit in Canada is high, as documented not only in this and other academic studies (Egeland et al., 2011; Huet et al., 2012; Council of Canadian Academies, 2014), but also in substantial recent press coverage (Rennie, 2014, 2015; Weber, 2014) and on social media (e.g., the Facebook group "Feeding my Family"). Given the current situation, researchers working on Inuit food security and related social and health issues have a responsibility to build assessment tools specific to Inuit, both to ensure that we do not misrepresent how Inuit experience food insecurity and so that culturally appropriate and effective policies can be developed. The results of this research demonstrate that to do this, we need to develop robust tools for measuring other dimensions of Inuit food security, including social support and harvesting knowledge, as well as access to resources for harvesting.

\section{ACKNOWLEDGEMENTS}

This research would not have been possible without the help of all of the Kangiqsujuarmiut who participated in the project, and particularly Amanda Annahatak who helped administer a large portion of the surveys. Pete Collings, Rebecca Bird, Jim Magdanz, Shauna BurnSilver, Elly Power, Mike Price, and the reviewers for Arctic provided helpful comments on earlier drafts of this article. Eugène Morin edited the French abstract. This research was supported by funding from the National Science Foundation Office of Polar Programs (award number PLR1303874), the Social Sciences and Humanities Research Council of Canada (award number 752-2010-1089), and a Stanford Interdisciplinary Graduate Fellowship provided by Mr. and Mrs. Phil Satre.

\section{REFERENCES}

Beaumier, M.C., and Ford, J.D. 2010. Food insecurity among Inuit women exacerbated by socio-economic stresses and climate change. Canadian Journal of Public Health 101(3):196-201.

Bickel, G., Nord, M., Price, C., Hamilton, W., and Cook, J. 2000. Guide to measuring household food security, revised 2000. Alexandria, Virginia: U.S. Department of Agriculture, Food and Nutrition Service.

http://www.fns.usda.gov/sites/default/files/FSGuide.pdf

Blanchet, C., and Rochette, L. 2008. Nutrition and food consumption among the Inuit of Nunavik. Nunavik Inuit Health Survey 2004, Qanuipitaa? How Are We? Québec: Institut national de santé publique du Québec and Nunavik Regional Board of Health and Social Services.

Briggs, J.L. 1970. Never in anger: Portrait of an Eskimo family. Cambridge, Massachusetts: Harvard University Press.

Brown, C.L., Magdanz, J.S., Koster, D.S., and Braem, N. 2012. Subsistence harvests in 8 communities in the Central Kuskokwim River Drainage, 2009. Technical Paper No. 365. Fairbanks: Alaska Department of Fish and Game, Division of Subsistence.
BurnSilver, S., Magdanz, J., Stotts, R., Berman, M., and Kofinas, G. 2016. Are mixed economies persistent or transitional? Evidence using social networks from Arctic Alaska. American Anthropologist 118(1):121 - 129.

http://dx.doi.org/10.1111/aman.12447

Cattell, R.B. 1966. The scree test for the number of factors. Multivariate Behavioral Research 1(2):245-276. http://dx.doi.org/10.1207/s15327906mbr0102_10

Chan, H.M., Fediuk, K., Hamilton, S., Rostas, L., Caughey, A., Kuhnlein, H., Egeland, G., and Loring, E. 2006. Food security in Nunavut, Canada: Barriers and recommendations. International Journal of Circumpolar Health 65(5):416-431. http://dx.doi.org/10.3402/ijch.v65i5.18132

Coates, J., Frongillo, E.A., Lorge Rogers, B., Webb, P., Wilde, P.E., and Houser, R. 2006. Commonalities in the experience of household food insecurity across cultures: What are measures missing? The Journal of Nutrition 136:1438S-1448S.

Collings, P. 2011. Economic strategies, community, and food networks in Ulukhaktok, Northwest Territories, Canada. Arctic 64(2):207-219.

http://dx.doi.org/10.14430/arctic4100

Collings, P., Marten, M.G., Pearce, T., and Young, A.G. 2016. Country food sharing networks, household structure, and implications for understanding food insecurity in Arctic Canada. Ecology of Food and Nutrition 55(1):30-49. http://dx.doi.org/10.1080/03670244.2015.1072812

Council of Canadian Academies. 2014. Aboriginal food security in northern Canada: An assessment of the state of knowledge. Ottawa: Expert Panel on the State of Knowledge of Food Security in Northern Canada, Council of Canadian Academies.

DeMars, C. 2010. Item response theory. Oxford: Oxford University Press. http://dx.doi.org/10.1093/acprof:oso/9780195377033.001.0001

Egeland, G.M., Johnson-Down, L., Cao, Z.R., Sheikh, N., and Weiler, H. 2011. Food insecurity and nutrition transition combine to affect nutrient intakes in Canadian Arctic communities. The Journal of Nutrition 141(9):1746-1753. http://dx.doi.org/10.3945/jn.111.139006

Fienup-Riordan, A. 1983. The Nelson Island Eskimo: Social structure and ritual distribution. Anchorage: Alaska Pacific University Press.

Ford, J.D. 2009. Vulnerability of Inuit food systems to food insecurity as a consequence of climate change: A case study from Igloolik, Nunavut. Regional Environmental Change 9(2):83-100. http://dx.doi.org/10.1007/s10113-008-0060-x

Ford, J.D., and Beaumier, M. 2011. Feeding the family during times of stress: Experience and determinants of food insecurity in an Inuit community. The Geographical Journal 177(1):44-61. http://dx.doi.org/10.1111/j.1475-4959.2010.00374.x

Fox, J., and Weisberg, S. 2011. An R companion to applied regression, 2nd ed. Thousand Oaks, California: SAGE Publications, Inc. 
Guyot, M., Dickson, C., Paci, C., Furgal, C., and Chan, H.M. 2006. Local observations of climate change and impacts on traditional food security in two northern aboriginal communities. International Journal of Circumpolar Health 65(5):403-415. http://dx.doi.org/10.3402/ijch.v65i5.18135

Hadley, C., Borgerhoff Mulder, M., and Fitzherbert, E. 2007. Seasonal food insecurity and perceived social support in rural Tanzania. Public Health Nutrition 10(6):544-551. http://dx.doi.org/10.1017/S1368980007246725

Harder, M.T., and Wenzel, G.W. 2012. Inuit subsistence, social economy and food security in Clyde River, Nunavut. Arctic 65(3):305-318. http://dx.doi.org/10.14430/arctic4218

Huet, C., Rosol, R., and Egeland, G.M. 2012. The prevalence of food insecurity is high and the diet quality poor in Inuit communities. The Journal of Nutrition 142(3):541-547. http://dx.doi.org/10.3945/jn.111.149278

Ikuta, H., Brown, C.L., and Koster, D.S., eds 2014. Subsistence harvests in 8 communities in the Kuskokwim River drainage and Lower Yukon River, 2011. Technical Paper No. 396. Fairbanks: Alaska Department of Fish and Game, Division of Subsistence.

Kuhnlein, H.V., Receveur, O., Soueida, R., and Berti, P.R. 2008. Unique patterns of dietary adequacy in three cultures of Canadian Arctic indigenous peoples. Public Health Nutrition 11(4):349-360.

Kukkonen, M., and Zimpelman, G. 2012. Subsistence harvests and uses of wild resources in Chistochina, Alaska, 2009. Technical Paper No. 370. Anchorage: Alaska Department of Fish and Game, Division of Subsistence.

Lambden, J., Receveur, O., Marshall, J., and Kuhnlein, H.V. 2006. Traditional and market food access in Arctic Canada is affected by economic factors. International Journal of Circumpolar Health 65(4):331-340. http://dx.doi.org/10.3402/ijch.v65i4.18117

Lawn, J., and Harvey, D. 2004. Nutrition and food security in Kanjiqsujuaq, Nunavik. Baseline survey for the Food Mail Pilot Project. Ottawa: Indian and Northern Affairs Canada.

Linacre, J.M. 2002. What do infit and outfit, mean-square and standardized mean? Rasch Measurement Transactions 16(2):878.

http://www.rasch.org/rmt/rmt162f.htm

Linacre, J.M., and Wright, B.D. 1994. Dichotomous infit and outfit mean-square fit statistics. Rasch Measurement Transactions $8(2): 360$.

http://www.rasch.org/rmt/rmt82a.htm

Loring, P.A., and Gerlach, S.C. 2009. Food, culture, and human health in Alaska: An integrative health approach to food security. Environmental Science \& Policy 12(4):466-478. http://dx.doi.org/10.1016/j.envsci.2008.10.006

Magdanz, J.S., Braem, N.S., Robbins, B.C., and Koster, D.S. 2010. Subsistence harvests in Northwest Alaska, Kivalina and Noatak, 2007. Technical Paper No. 354. Kotzebue: Alaska Department of Fish and Game, Division of Subsistence.
Mair, P., and Hatzinger, R. 2007. Extended Rasch modeling: The eRm package for the application of IRT models in R. Journal of Statistical Software 20(9), $20 \mathrm{p}$. http://dx.doi.org/10.18637/jss.v020.i09

Mair, P., Reise, S.P., and Bentler, P.M. 2007. IRT goodness-offit using approaches from logistic regression. Los Angeles: Department of Statistics, UCLA.

Power, E.M. 2008. Conceptualizing food security for aboriginal people in Canada. Canadian Journal of Public Health 99(2):95-97.

R Development Core Team. 2012. R: A language and environment for statistical computing. Vienna: R Foundation for Statistical Computing. http://www.R-project.org

Ready, E. 2016. Food, sharing, and social structure in an Arctic mixed economy. PhD dissertation, Stanford University, Stanford, California.

Rennie, S. 2014. Nunavut's food problems prompt intense scrutiny, hopes for change. CBC News Online, December 14. http://www.cbc.ca/news/world/nunavut-s-food-problemsprompt-intense-scrutiny-hopes-for-change-1.2872977

—__ 2015. Nunavut's hunger problem: 'We can't pretend it doesn't exist anymore.' CBC News Online, January 24.

http://www.cbc.ca/news/canada/north/nunavut-s-hungerproblem-we-can-t-pretend-it-doesn-t-exist-anymore-1.2929573

Revelle, W. 2015. psych: Procedures for psychological, psychometric, and personality research. R package version 1.5.1. Evanston, Illinois: Northwestern University.

Rizopoulos, D. 2006. 1tm: An R package for latent variable modeling and item response analysis. Journal of Statistical Software 17(5), $25 \mathrm{p}$. http://dx.doi.org/10.18637/jss.v017.i05

Smith, E.A. 1991. Inujjuamiut foraging strategies: Evolutionary ecology of an Arctic hunting economy. New York: Aldine de Gruyter.

Smith, T.G., and Wright, H. 1989. Economic status and role of hunters in a modern Inuit village. Polar Record 25(153):93 - 98. http://dx.doi.org/10.1017/S003224740001038X

Statistics Canada. 2012. Census profile, 2011 Census. Catalogue No. 98-316-XWE. Ottawa: Statistics Canada.

http://www12.statcan.gc.ca/census-recensement/2011/dp-pd/ prof/index.cfm?Lang $=\mathrm{E}$

Stevenson, M.G. 1997. Inuit, whalers, and cultural persistence: Structure in Cumberland Sound and Central Inuit social organization. Oxford: Oxford University Press.

Urke, H.B., Cao, Z.R., and Egeland, G.M. 2014. Validity of a single item food security questionnaire in Arctic Canada. Pediatrics 133(6):e1616-e1623. http://dx.doi.org/10.1542/peds.2013-3663

USDA (U.S. Department of Agriculture). 2012. U.S. household food security survey module: Six item short-form. Washington, D.C.: USDA, Economic Research Service.

http://www.ers.usda.gov/datafiles/Food_Security_in_the United States/Food Security Survey_Modules/short2012. pdf 
Van der Gaag, M., and Snijders, T.A.B. 2005. The resource generator: Social capital quantification with concrete items. Social Networks 27(1):1-29.

http://dx.doi.org/10.1016/j.socnet.2004.10.001

Venables, W.N., and Ripley, B.D. 2002. Modern applied statistics with S, 4th ed. New York: Springer. http://dx.doi.org/10.1007/978-0-387-21706-2

Weber, B. 2014. Hunger makes Quebec Inuit shorter than average: Study. CBC News Online, August 28.

http://www.cbc.ca/news/canada/north/hunger-makes-quebecinuit-shorter-than-average-study-1.2749118

Wenzel, G.W. 1991. Animal rights, human rights: Ecology, economy and ideology in the Canadian Arctic. Toronto: University of Toronto Press.
Wesche, S.D., and Chan, H.M. 2010. Adapting to the impacts of climate change on food security among Inuit in the Western Canadian Arctic. EcoHealth 7(3):361 - 373. http://dx.doi.org/10.1007/s10393-010-0344-8

Wolfe, R.J. 1987. The super-household: Specialization in subsistence economies. Paper presented at the 14th Annual Meeting of the Alaska Anthropological Association, 12-13 March 1987, Anchorage, Alaska.

Wright, B.D., and Linacre, J.M. 1994. Reasonable mean-square fit values. Rasch Measurement Transactions 8(3):370.

Wunderlich, G.S., and Norwood, J.L., eds. 2006. Food insecurity and hunger in the United States: An assessment of the measure. Panel to Review the U.S. Department of Agriculture's Measurement of Food Insecurity and Hunger. Washington, D.C.: The National Academies Press. 